\title{
Seasonal Variation in Particulate Matter and Gaseous Pollutant Concentration in Bangalore City
}

\author{
Tejaswi Kumar G, Sumanth Reddy, Umesh C, T.V. Amogh, Priyanka A \\ (Assistant Professor) \\ Dayananda Sagar College of Engineering
}

\begin{abstract}
With the ever-increasing pollution in mega cities, statistical modelling of pollutants has become a major part of the study. The current paper focuses on the study carried out to investigate the effects of meteorological conditions on atmospheric pollutant concentration in Bangalore city. While sudden increase in the emission of pollutants influences pollution episodes in urban area, the contribution of unfavorable meteorological conditions cannot be ignored. These unfavorable conditions may reduce the ability of the atmosphere to disperse pollutants and transport from other areas. This paper aims to estimate the impacts due to air pollutant concentration in Bangalore throughout the seasons and determine the primal meteorological factors that influence air pollution and quantify their impact on the air pollution levels in the city.
\end{abstract}

\section{I.INTRODUCTION}

\section{A. Background}

Air pollution is among the primary concerns in the world that is rapidly increasing with time. The need to perform analysis on the various meteorological factors is evident as these reduce the ability of the atmosphere to disperse significant concentrations of pollutants to other areas. Statistical modelling can be employed to analyze the current pollution levels and their causes. Furthermore, informed decisions can be made that would aid in framing policies by the environmental agencies of the government. Such studies would be conducive in implementing ad-hoc solutions to specific pollutants that majorly contribute to air pollution. The relationship between certain meteorological factors and pollutants can also be determined that would further aid in implementing better solutions to tackle the same.

\section{B. Analysis}

The analysis of pollutants includes collection of pollutant concentration profiles and plotting them against several meteorological factors such as wind speed, wind direction, rainfall, humidity, temperature, and so on. Such study would help in determining recent trends and establishing relationships between pollutants and certain meteorological factors. Statistical modeling is also done in order determine the association between the factors and pollutants. The variance in the concentration of pollutants by anthropogenic activities is often ignore in studies that share the characteristic similarities as the current one.

It is becoming evident that anthropogenic aerosols exert a radiative influence on climate that is globally comparable to that of greenhouse gases but opposite in sign. However, this aerosol radiative influence has received much less attention than forcing by anthropogenic greenhouse gases. An increasing interest has recently emerged for using visibility measurements as a substitute for measurements of the levels of atmospheric pollutants. The backscattering and absorption are the two phenomena that are deeply associated with the reduction.

in the visibility of air. The tiny particles when encountered by sunlight result in atmospheric visibility degradation. Thus, coexistence of dust, industrial and biomass burning pollutants complicates the visibility degradation mechanism

\section{II.RELATED WORKS}

\section{A. Early Work}

In 1984, S A Twomey, M Piepgrass and T L Wolfe worked on significantly establishing a strong relationship between pollution and cloud drop concentration. Furthermore, the effect is much significant than previously assumed. The absorption-to-concentration relationship of a previous study overestimated absorption. The nuclei which are active in cloud condensation are believed to be composed of ammonium sulfate or a similar compound. [1]

The primary goal of this measurement program was to obtain a near perfect relationship in circumstances of the least pollution level. The results suggest that an increase of about 0.1 in planetary albedo could achieve an increase from present-day levels to existing levels in more polluted regions of the containers. [1]

\section{B. Recent work}

The influence of meteorological factors on the pollution level of a city was further studied by conducting various observations. Visibility was observed at more than 600 synoptic weather stations. The visibility data was were screened for precipitation recorded and excluded when humidity exceeded 90\%. [2]

The quantification of aerosol radiative forcing and of its relation to anthropogenic emissions requires globally representative measurements of aerosols. The direct aerosol and indirect cloud components each contribute a rough $1 \mathrm{~W} / \mathrm{m}^{2}$ that is associated only with $\mathrm{NH}$. However, aerosol forcing varies significantly in characteristics from green-house gas forcing. [3]

The factor of extinction coefficient was employed to study the trends associated with the atmospheric haze A relative 
correction factor was applied to compensate the effect of relative humidity when achieving the dry extinction coefficient. The burning of fossil fuels, lower mixing height and a stable weather in the weather contributed to the higher Particulate Matter concentration and lower visibility. [4]

The microphysical and radiative properties in air alters the environmental pollution levels. Especially, the presence of Cloud Condensation Nuclei loads reduce the cloud droplet size and subsequently suppress precipitation in shallow and shortlived clouds. Careful studies revealed the degrading effect caused by anthropogenic aerosols. A high-resolution widerange particle spectrometer was employed to observe particle size distributions in the size range of $10 \mathrm{~nm}-10 \mu \mathrm{m}$. The relationship between $\mathrm{N}_{\mathrm{CCN}}, \mathrm{N}_{\mathrm{CN}}$ and $\mathrm{N}_{\mathrm{CCN}} / \mathrm{N}_{\mathrm{CN}}$ varied under a go-haze co-occurring condition, as well as the major influential factors to these activities. [5]

In order to determine the physical and chemical properties of haze aerosols besides determining the primary water-soluble inorganic ions in aerosols and haze gases. The quantitative characterization of aerosol composition and trace gases is performed revealing the significant contribution of nitrate and sulphate towards aerosol pollution events. The daily concentration analysis of water-soluble ions and gaseous precursors provides significant insights into exactly determine the contributors in pollution levels in major cities. [6]

The analysis of a comprehensive data set of one month of simultaneous measurements of aerosol size spectra, black carbon, $\mathrm{N}_{\mathrm{CCN}}$, water-soluble ions and gaseous pollutants paved the way for an effective $\mathrm{CCN}$ prediction model. The conduction of closure study investigates the influence of aerosol chemical composition on its growth to $\mathrm{CCN}$. [7]

Light scattering efficiencies of sulphate, nitrate, organic carbon, and elemental carbon were determined based on the size distributions measured at times of visibility impairment. Various forms of meteorological conditions that cause visibility degradation are associated with distinct fine particle size distributions. [8]

Filtration efficiencies for two aerosol types considering size selection and total concentration were determined. Analysis of variance with pairwise post-hoc comparisons for differentiating among aerosol type, particle size and air purifier model. Size distributions of diesel and KCL varied with diesel having higher concentrations in smaller ultrafine region. [9]

The analysis of PM10 trends in ozone attainment and nonattainment areas was made to account for the most prevalent fine materials such as Sulphates, Organic Carbon, Nitrates and Ammonium. The weighted arithmetic mean concentration and $95^{\text {th }}$ percentile for 24 -hour concentrations were employed to get statistical insights on PM10 trends. [10]

\section{III.METHODOLOGY}

The determination of pollutant concentration trends in different months leads to the development of relationship between various meteorological factors and anthropogenic activities. The statistical analysis of aerosols and gaseous precursors is necessary in quantifying the impacts of certain air pollutants, especially PM (Particulate Matter). [4]
The proposed study involves the collection of concentration profiles of $\mathrm{PM}\left(\mathrm{PM}_{10}\right.$ and $\left.\mathrm{PM}_{2.5}\right), \mathrm{SO} 2$ and $\mathrm{NO} 2$ in Bangalore city. The data used in this study were compiled from monthly records for the period Jan 2019-Dec2019. The statistical model was developed for particulate matters and meteorological parameters and correlation was developed between $\mathrm{PM}_{2.5}$ and $\mathrm{PM}_{10}$ for pre monsoon, monsoon and post monsoon.

The sampling program of suspended particles $\left(\mathrm{PM}_{10}\right.$ and $\mathrm{PM}_{2.5}$ ) and gaseous pollutants (SO2 and NO2) was started in Jan 2019 - Dec 2019 at three sampling stations on 24 hourly basis with an interval of 8 hours for change of filter paper for $\mathrm{PM}_{10}$ and 5 days for $\mathrm{PM}_{2.5}$. Both suspended particles ( $\mathrm{PM}_{10}$ and $\mathrm{PM}_{2.5}$ ) and gaseous pollutants (SO2 and $\mathrm{NO} 2$ ) were transferred into air-tight box and transported to KPSCB Laboratory, M.G Road Bangalore for analysis. Analysis was carried out with standard experimental procedure prescribed by Central Pollution Control Board, India.

The monthly mean variables of $\mathrm{PM}_{10}, \mathrm{PM}_{2.5}, \mathrm{SO} 2$ and $\mathrm{NO} 2$ concentrations are obtained from taking from daily mean average from Jan 2019 - Dec 2019 over Bangalore city depicted in the following tables 1-3 for different sampling stations.

\begin{tabular}{|l|l|l|l|l|}
\hline MONTH & PM $_{\mathbf{1 0}}$ & $\mathbf{P M}_{\mathbf{2 . 5}}$ & $\mathbf{S O 2}$ & NO2 \\
\hline JANUARY & 143 & 60 & 2 & 42 \\
\hline FEBRUARY & 152 & 64 & 2 & 44 \\
\hline MARCH & 141 & 52 & 2 & 40 \\
\hline APRIL & 0 & 0 & 2 & 35 \\
\hline MAY & 0 & 0 & 2 & 31 \\
\hline JUNE & 0 & 0 & 2 & 0 \\
\hline JULY & 126 & 0 & 2 & 33 \\
\hline AUGUST & 142 & 0 & 2 & 31 \\
\hline SEPTEMBER & 113.9 & 0 & 2 & 33.4 \\
\hline OCTOBER & 122 & 0 & 2 & 34 \\
\hline NOVEMBER & 146 & 0 & 2 & 31.5 \\
\hline DECEMBER & 103 & 0 & 2 & 33 \\
\hline
\end{tabular}

Table.1 Monthly variations in Central Silk Board

\begin{tabular}{|l|l|l|l|l|}
\hline MONTH & PM $_{\mathbf{1 0}}$ & $\mathbf{P M}_{\mathbf{2 . 5}}$ & $\mathbf{S O 2}$ & $\mathbf{N O 2}$ \\
\hline JANUARY & 121 & 53 & 2 & 35 \\
\hline FEBRUARY & 135 & 63 & 2 & 37 \\
\hline MARCH & 106 & 50 & 2 & 35 \\
\hline APRIL & 101 & 48 & 2 & 31 \\
\hline MAY & 71 & 37 & 2 & 31 \\
\hline JUNE & 0 & 0 & 0 & 0 \\
\hline JULY & 0 & 0 & 0 & 0 \\
\hline AUGUST & 85 & 42 & 2 & 30 \\
\hline SEPTEMBER & 0 & 0 & 0 & 0 \\
\hline OCTOBER & 104 & 49 & 2 & 35 \\
\hline NOVEMBER & 89 & 37 & 2 & 33.3 \\
\hline DECEMBER & 107 & 48 & 2 & 32 \\
\hline
\end{tabular}

Table.2 Monthly variations in Peenya Industrial

\begin{tabular}{|l|l|l|l|l|}
\multicolumn{7}{|c}{ Area } \\
\hline MONTH & PM $_{\mathbf{1 0}}$ & PM $_{\mathbf{2 . 5}}$ & SO2 & NO2 \\
\hline JANUARY & 86 & 45 & 2 & 27 \\
\hline FEBRUARY & 86 & 41 & 2 & 23 \\
\hline MARCH & 98 & 49 & 2 & 22 \\
\hline APRIL & 0 & 0 & 0 & 0 \\
\hline MAY & 71 & 35 & 2 & 22 \\
\hline JUNE & 62 & 29 & 2 & 20 \\
\hline JULY & 0 & 39 & 0 & 0 \\
\hline AUGUST & 0 & 34 & 0 & 0 \\
\hline SEPTEMBER & 0 & 29.5 & 0 & 0 \\
\hline OCTOBER & 77 & 33 & 2 & 23 \\
\hline NOVEMBER & 79 & 0 & 2 & 26.9 \\
\hline DECEMBER & 67 & 0 & 2 & 26 \\
\hline
\end{tabular}

Table. 3 Monthly variations in Banaswadi 
The empirical analysis of suspended particles $\left(\mathrm{PM}_{10}\right.$ and $\mathrm{PM}_{2.5}$ ) and gaseous pollutants (SO2 and NO2) samples is done with reference to the above tables. Meteorological parameters such as humidity, rainfall, wind speed and temperature were collected from Indian Meteorological Department (IMD), Bangalore.

The correlation coefficients between mass concentrations of

$\mathrm{PM}_{10}$ and $\mathrm{PM}_{2.5}, \mathrm{SO} 2, \mathrm{NO} 2$ and average meteorological factors: wind speed and relative humidity. [4]

\section{IV.CONCLUSION}

The purpose of this project was to quantify the impacts of air pollutants, $\mathrm{PM}\left(\mathrm{PM}_{10}\right.$ and $\left.\mathrm{PM}_{2.5}\right)$ samples, $\mathrm{SO} 2$ and $\mathrm{NO} 2$ were collected from different parts of Bangalore city during the period Jan 2019 - Dec 2019. The study has shown the pollution in terms of particulate matter $\left(\mathrm{PM}_{10}\right.$ and $\left.\mathrm{PM}_{2.5}\right)$, exceeding the NAAQS standard. Analysis of correlation between $\mathrm{PM}_{10}, \mathrm{PM}_{2.5}, \mathrm{SO} 2$ and $\mathrm{NO} 2$ with meteorological parameters (wind speed, humidity). A positive correlation was observed between $\mathrm{PM}_{10}$ and $\mathrm{PM}_{2.5}$ with a correlation coefficient of 0.9993 samples collected across Bangalore city. Correlation coefficient of 0.998 concludes that as $\mathrm{PM}_{10}$ concentration increases, $\mathrm{PM}_{2.5}$ concentrations also increase in the atmosphere. Single dimensional model was developed for $\mathrm{PM}_{10}, \mathrm{PM}_{2.5}, \mathrm{SO} 2$ and $\mathrm{NO} 2$ by using SPSS software. By using these models $\mathrm{PM}_{10}$ concentrations can be predicted if $\mathrm{PM}_{2.5}$, $\mathrm{SO} 2, \mathrm{NO} 2$ values are known. $\mathrm{SO} 2$ and $\mathrm{NO} 2$ concentration during are within permissible limit. The study concludes that in Bangalore city the impact of SO2 and NO2 are least. From the study it is concluded that PM concentration decreases substantially during monsoon. The scanty rainfall and absence of clouds during post-monsoon increases PM concentration but in pre-monsoon due to inversion effect there is a high concentration of PM. During monsoon, the wet removal process is most effective and the PM concentration reaches its minimum. The land remains wet and the sky is generally cloudy and diurnal variation in air temperature is the lowest and PM get washed away by rain. The washout process removes both large and small particles, the larger ones more effectively. The results obtained may support future policies directed at emissions control in Bangalore city. However, there are some limitations of the study because of the constraint in the financial budget heavy metals study during the period could not be analyzed.

\section{REFERENCES}

[1] S.A. Twomey, M. Piepgrass, T.L. Wolfe, "An assessment of the impact of pollution on global cloud albedo",1983.

[2] Di Chang, Yu Song, Bing Liu, "Visibility trends in six megacities in China 1973 - 2007”, 2009.

[3] R.J Charleson, S.E. Schwartz, J.M. Hales, R.D. Cess, J.A. Coakley, Jr., J.E. Hansen, D.J. Hofmann, "Climate Forcing by Anthropogenic Aerosols", 1992.

[4] Huizheng Che, Xiaoye Zhang, Yang Li, Zijiang Zhou, John J, Xianjun Hao, "Haze trends over the capital cities of 31 provinces in China, 1981 - 2005" 2008.

[5] C. Leng, Q. Zhang, D. Zhang, C. Xu, T. Cheng, R. Zhang, J. Tao, J. Chen, S. Zha, Y. Zhang, X. Li, L. Kong, W. Gao, "Variations of cloud condensation nuclei $(\mathrm{CCN})$ and aerosol activity during fog-haze episode: a case study from Shanghai", 2014

[6] Huanhuan DU, Lingdong Kong, Tiantao Cheng, Jianmin Chen, Jianfei Du, Ling Li, Xiangao Xia, Chunpeng Leng, Guanghan Huang, "Insights into summertime haze pollution events over Shanghai based on online water-soluble ionic composition of aerosols", 2011.

[7] C. Leng, Q. Zhang, J. Tao, H. Zhang, D. Zhang, C. Xu, X. Li, L. Kong, T. Cheng, R. Zhang, X. Yang, J. Chen, L. Qiao, S. Lou, H. Wang, and C. Chen, "Impacts of new particle formation on aerosol cloud condensation nuclei (CCN) activity in Shanghai: case study", 2014.

[8] Christine S. Sloane, John Watson, Judith Chow, Lyle Pritchett, L. Willards Richards, "Size segregated fine particle measurements by chemical species and their impact on visibility impairment in Denver", 1991

[9] R.L. Peck, S.A. Grinshpun, M. Yermakov, M.B. Rao, J. Kim, T. Reopen, "Efficiency of portable HEPA air purifiers against traffic related combustion particles", 2016.

[10] Thomas L. Darlington, Dennis F. Kahlbaum, Jon M. Heuss, George T. Wolff, "Analysis of $\mathrm{PM}_{10}$ Trends in the United States from 1988 through 1995", 2011. 